\title{
Impact Damage Characteristics of Carbon Fibre Metal Laminates: Experiments and Simulation
}

\author{
Y. Shi ${ }^{1} \cdot$ C. Pinna ${ }^{2} \cdot$ C. Soutis ${ }^{3}$
}

Received: 4 February 2020 / Accepted: 26 March 2020 / Published online: 8 May 2020

(C) The Author(s) 2020

\begin{abstract}
In this work, the impact response of carbon fibre metal laminates (FMLs) was experimentally and numerically studied with an improved design of the fibre composite lay-up for optimal mechanical properties and damage resistance. Two different stacking sequences (Carall 3-3/2-0.5 and Carall 5-3/2-0.5) were designed and characterised. Damage at relatively low energy impact energies $(\leq 30 \mathrm{~J})$ was investigated using Ultrasonic C-scanning and X-ray Computed Tomography (X-RCT). A 3D finite element model was developed to simulate the impact induced damage in both metal and composite layers using Abaqus/Explicit. Cohesive zone elements were introduced to capture delamination occurring between carbon fibre/epoxy plies and debonding at the interfaces between aluminium and the composite layers. Carall 5-3/2-0.5 was found to absorb more energy elastically, which indicates better resistance to damage. A good agreement is obtained between the numerically predicted results and experimental measurements in terms of force and absorbed energy during impact where the damage modes such as delamination was well simulated when compared to non-destructive techniques (NDT).
\end{abstract}

Keywords Fibre metal laminates (FMLs) · Impact damage · Damage assessment · Ultrasonic Cscan $\cdot \mathrm{X}$-ray computed tomography $(\mathrm{X}-\mathrm{RCT})$, finite element analysis, cohesive zone elements

\section{Introduction}

The drive for high-performance lightweight structures has led to the development of fibre metal laminates (FMLs) [1] made of thin metal sheets combined with fibre reinforced

\section{Soutis}

constantinos.soutis@manchester.ac.uk

1 Department of Mechanical Engineering, University of Chester, Thornton Science Park, Pool Lane, Chester $\mathrm{CH} 2$ 4NU, UK

2 Department of Mechanical Engineering, The University of Sheffield, Mappin Street, Sheffield S1 3JD, UK

3 Aerospace Research Institute, The University of Manchester, Sackville Street, Manchester M13 9PL, UK 
polymers [2]. This hybrid structure offers improved mechanical properties, by combining the benefits from both metal and composite components, such as good compression, impact and fatigue properties with excellent damage resistance due to the effect of crack bridging, which can significantly slow down crack growth. In particular, the fibre reinforced composite layers can reduce stresses in metal layers and therefore, help to absorb more impact energy compared to monolithic metallic materials when subjected to external impact loading to exhibit a high penetration resistance. Depending on such benefits of mechanical properties improved, FMLs have been widely used for applications in aircraft structures, such as the commercially developed Glare in skin panels for the fuselage of Airbus A380.

As competition for the application of this kind of hybrid composite structures to aircraft is growing, the characterisation and understanding of their damage resistance with respect to dynamic impact loads is of prime importance in order to extend the lifetime and applications of FMLs. Therefore, great effort has been made to develop the new generation of FMLs by replacing either the metal or composite layers or even both. Many types of fibres such as carbon, ceramics, synthetics, organics and silicon carbide fibres are available for new FMLs [3]. The type of resins is also crucial in determining the bonding quality, mechanical properties and durability of FMLs. Additionally, the metal sheets used as cover material normally include aluminium and titanium, although ceramics and high strength steels have also been used for specific applications like ballistic protection [1]. In this work, carbon fibres/epoxy prepreg combined with aluminium sheets was used as FML, which is named Carbon/aluminium laminates (Carall), instead of glass fibre/epoxy layers used in the commercially developed Glare. A significant advantage of Carall is its extreme efficiency in damage resistance through crack bridging, due to the high stiffness of carbon fibres, which leads to relatively low crack growth rates.

Although Carall offers great potential for next generation composite structures with improved mechanical properties, very few studies on the characterisation of their properties can be found in the literature [4-11]. According to Vermeeren [12], T800 carbon fibres contributed to a $40 \%$ increase in the ultimate tensile strength of Carall compared to that of Glare while a value of $100 \mathrm{GPa}$ for the elastic modulus was measured, which was almost twice that of Glare (55 GPa). Carall also exhibited good fatigue property, especially under high cycle loading [12]. The impact behaviour of FMLs is one of the main concerns for aerospace applications especially during assembly, maintenance and service life of aircraft structures. Moreover, the detailed progress of various damage modes was hardly to know as it is difficult to be experimentally captured. However, only few published studies can be found for the impact assessment of FMLs [13-24], with very scarce information about Carall in experimental and numerical methods.

Therefore, in this work, the impact behaviour and damage characteristics of Carall were experimentally and numerically studied with two different lay-up of composite layers designed with reference to the design standards for Glare. Low velocity impact tests were performed for both structures with two impact energy levels. The impact induced damage was non-destructively characterised using ultrasonic C-Scan as well as advanced 3D X-ray computed tomography (X-RCT) to recognise the internal damage modes of FMLs such as cracks within composite layers and delamination at the interfaces. A numerical model was developed to simulate the damage modes in both metal and composite layers using the commercial FE software Abaqus/Explicit. Intra-laminar damage modes in the composite layers were modelled through a damage model developed by Shi et al. [25] while the damage in metallic layers was predicted using a ductile damage model [26]. Cohesive zone elements [25-29], inserted at the interfaces between plies within each composite layers and between metal and 
composite layers, were used to model delamination and debonding. Predicted damage was compared to $\mathrm{C}$-scan and $\mathrm{CT}$ scan results to assess the performance of the developed numerical model.

\section{Experiments}

\subsection{Preparation of Hybrid Composite Laminates}

In this work, FMLs combining aerospace grade carbon fibre/epoxy layer (HTS40/977-2) with aluminium Al1050 was manufactured in an autoclave system. MTA 240 adhesive film was used to improve the bonding quality between aluminium and carbon fibre composite layers at the interface but also to isolate aluminium from carbon fibre composite layers so that galvanic corrosion resulting from direct contact between these two components can be effectively avoided.

Two different structures, shown in Fig. 1, were designed by reference to the grades of commercially available Glare [1]:

- Carall 3-3/2-0.5 - [Al/MTA/(0/90)/MTA/Al/MTA/(90/0)/MTA/Al]

- Carall 5-3/2-0.5 - [Al/MTA/(0/90/90/0)/MTA/Al/MTA/(0/90/90/0)/MTA/Al]

\begin{tabular}{|c|c|}
\hline $\begin{array}{l}\text { Impactec } \\
\text { surface }\end{array}$ & \\
\hline Aluminium $-0.5 \mathrm{~mm}$ & Aluminium - 0.5mm \\
\hline MTA $240-0.25 \mathrm{~mm}$ & MTA $240-0.25 \mathrm{~mm}$ \\
\hline CFRP $0^{\circ}$ ply $-0.25 \mathrm{~mm}$ & CFRP $0^{\circ}$ ply $-0.125 \mathrm{~mm}$ \\
\hline CFRP $90^{\circ}$ ply $-0.25 \mathrm{~mm}$ & $\begin{array}{l}\text { CFRP } 90^{\circ} \text { ply }-0.25 \mathrm{~mm} \\
\text { CFRP } 0^{\circ} \text { ply }-0.125 \mathrm{~mm}\end{array}$ \\
\hline MTA $240-0.25 \mathrm{~mm}$ & MTA $240-0.25 \mathrm{~mm}$ \\
\hline Aluminium - $0.5 \mathrm{~mm}$ & Aluminium - $0.5 \mathrm{~mm}$ \\
\hline MTA $240-0.25 \mathrm{~mm}$ & MTA $240-0.25 \mathrm{~mm}$ \\
\hline CFRP $90^{\circ}$ ply $-0.25 \mathrm{~mm}$ & CFRP $0^{\circ}$ ply $-0.125 \mathrm{~mm}$ \\
\hline CFRP $0^{\circ}$ ply $-0.25 \mathrm{~mm}$ & $\begin{array}{c}\text { CFRP } 90^{\circ} \text { ply }-0.25 \mathrm{~mm} \\
\text { CFRP } 0^{\circ} \text { ply }-0.125 \mathrm{~mm}\end{array}$ \\
\hline MTA $240-0.25 \mathrm{~mm}$ & MTA $240-0.25 \mathrm{~mm}$ \\
\hline Aluminium - 0.5mm & Aluminium $-0.5 \mathrm{~mm}$ \\
\hline
\end{tabular}

a. Carall 3-3/2-0.5

b. Carall 5-3/2-0.5

Fig. 1 Schematics of two grades of hybrid aluminium-carbon fibre epoxy laminates identified as Carall 3-3/20.5 and Carall 5-3/2-0.5 
Carall 3-3/2-0.5 has three $0.5 \mathrm{~mm}$ thick layers of aluminium with two $0.250 \mathrm{~mm}$ thick fibre/epoxy laminate layers interlaced with a $0^{\circ} / 90^{\circ}$ stacking sequence. As for Carall 5-3/20.5 , the same three layers of aluminium as for Carall 3-3/2- 0.5 are combined with two fibre/ epoxy layers stacked with a symmetry of $0^{\circ} / 90^{\circ} / 90^{\circ} / 0^{\circ}$ and with an individual ply thickness of $0.125 \mathrm{~mm}$ (half that of Carall 3-3/2-0.5), Therefore the total thickness of both laminates is the same. For both structures, the rolling direction of the aluminium layers was aligned with the fibre direction of the $0^{\circ}$ plies.

\subsection{Impact Test}

The manufactured Carall plate was cut into $100 \times 100 \mathrm{~mm}^{2}$ specimens ready for impact tests. The impact testing followed the guidelines given by the ASTM D7136/D7136M-07 standard [30]. A drop weight impact tower was used for all impact tests, with a drop mass of $2 \mathrm{~kg}$ and increased drop heights of 0.5 and $1.5 \mathrm{~m}$ resulting in different impact energies of 9.8 and $29.4 \mathrm{~J}$, respectively. The impact test machine is shown in Fig. 2. In Fig. 2(a) the height scale vertically stands on both sides of the rig to help the verification of impact height during experiments with two rails parallel to the height scale guiding the impactor for a free fall. Movable rails are also designed horizontally and perpendicularly to adjust the impact location on the targeted sample. In Fig. 2(b), the close-up view of the mounted impactor is shown. The impact weight can be changed by adding or removing weight blocks. The stainless rigid tup is designed as a hemispherical head with a diameter of $15 \mathrm{~mm}$. A force ring sensor PCB 203B SN 2205 is embedded in the head and connected to the dynamic signal analyser SigLab to record the
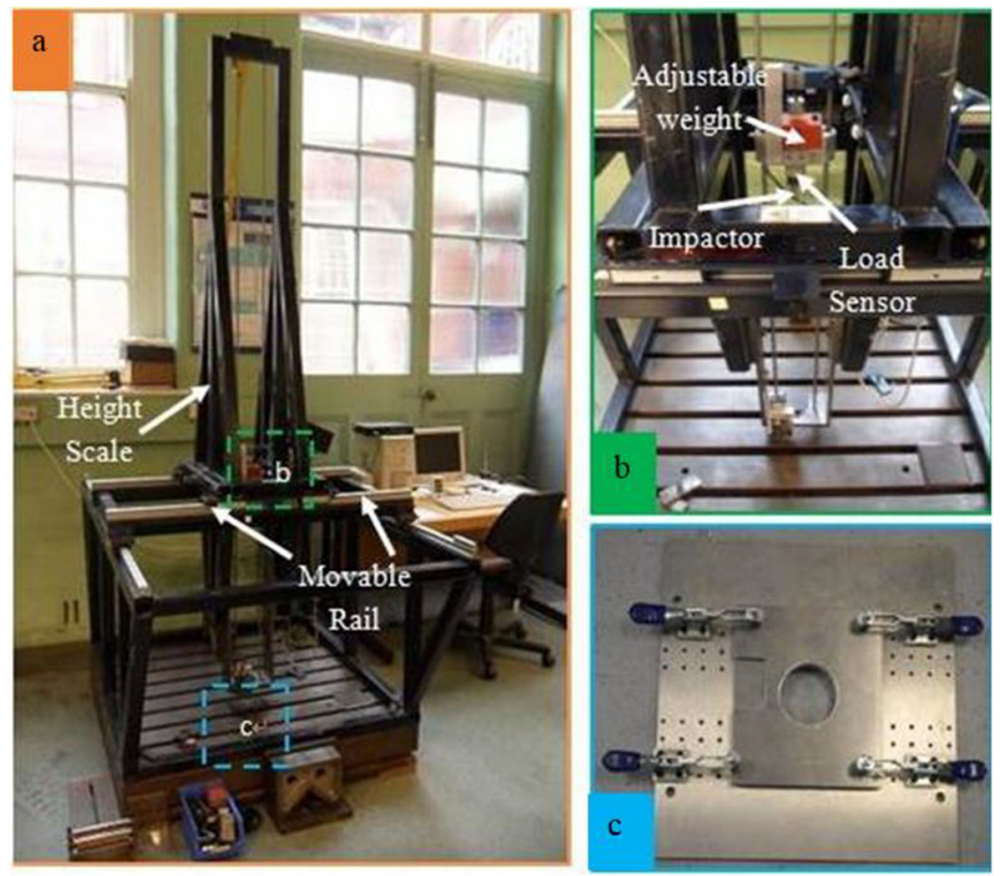

Fig. 2 Drop weight impact test machine a Drop weight impact tower; $\mathbf{b}$ Local view of impactor with load sensor; c clamp design 
dynamic loading history when it is triggered. A computer with a specific program developed using Matlab is linked to the measuring device SigLab to acquire and process the recorded data. A specifically designed clamp with a circular hole of $75 \mathrm{~mm}$ in diameter in the central part is applied to fix the samples during impact tests, as shown in Fig. 2(c).

The impact force is recorded by the force sensor during impact. The acceleration of the impactor is thus derived by dividing the measured force by the impact mass. Additional required variables can be obtained based on this calculated acceleration, such as velocity, displacement and impact energy. For instance, if the mass of the impactor is $m$ with an initial velocity of $v_{0}$, the impact energy can be easily calculated by:

$$
E=\frac{m v_{0}^{2}}{2}
$$

The absorbed energy of the impacted samples can be thus derived as:

$$
E_{\text {absorbed }}=E-\frac{m v_{i}^{2}(t)}{2}=\frac{m v_{0}^{2}}{2}-\frac{m v_{i}^{2}(t)}{2}
$$

where $v_{i}(t)$ is the velocity of the impactor at time $t$ during impact and can be obtained as:

$$
v_{i}(t)=v_{0}-\frac{1}{m} \int_{0}^{t} F d t
$$

$F \mathrm{n}$ the above equation is the force measured during the impact test. An electrical output can be recorded by the force ring sensor with a sensitivity of $0.0562 \mathrm{mV} / \mathrm{N}$. The force as well as acceleration of the impactor can then be easily obtained based on the measured electrical output during impact.

\subsection{Non-destructive Testing (NDT)}

Following the impact tests, ultrasonic C-Scans and X-Ray computed tomography (X-RCT) were used for NDT to detect impact induced internal damages in composite structures.

Firstly, the ultrasonic C-Scan was used to find out the total damage extent in composite plates resulting from the various impact loading cases. Measurements were performed at the National Composites Certification and Evaluation Facility (NCCEF) at the University of Manchester, using a $5 \mathrm{MHz}$ probe in transmission mode with a water coupling agent generated by a water-jet system to assist the test.

The X-Ray computed tomography (X-RCT) technique was also used to accurately observe detailed internal damage extent and location. In this work, the impacted specimens were scanned at the Henry Moseley X-ray Imaging Facility at the University of Manchester using the Nikon Metrology 225/320 kV Custom Bay system. X-rays were generated with a Mo target using a voltage of $90 \mathrm{kV}$ and a current of $110 \mu \mathrm{A}$. The data acquisition was performed with an exposure time of $1000 \mathrm{~ms}$, a $1 \mathrm{~mm}$ thickness Al filter, and a series of 3142 projections. A voxel size of $22.5 \mu \mathrm{m}$ was used for an impact energy of $9.8 \mathrm{~J}$ and of $34.7 \mu \mathrm{m}$ for energy level of $29.4 \mathrm{~J}$. The methodology to obtain the through-thickness damage evolution was adapted to impact damage characterisation from the work of Léonard et al. [31, 32] for assessing damages in composite impacted panels. The commercial software Avizo ${ }^{\circledR}$ Fire version 7.1, designed specifically for scientific visualisation and industrial inspection, was used for post processing and analysis of data. In order to fit the limited resolution field of X$\mathrm{RCT}$, the impacted samples were cut down to coupon size of $45 \times 45 \mathrm{~mm}$ (Impact energy of 
$9.8 \mathrm{~J})$ and $70 \times 70 \mathrm{~mm}(29.4 \mathrm{~J})$. A particular challenge for the characterisation of damage in Carall using X-RCT is to generate enough energy to penetrate the metal layers while obtaining adequate contrast to resolve matrix cracks in composite layers.

\section{Numerical Simulation}

\subsection{Material Damage Model}

The composite damage model developed by Shi et al. [25] is used in this work to model the intra-laminar damage modes. The damage criteria used for the four main damage modes, fibre tensile and compressive failure and matrix tensile and compressive failure, are briefly introduced in this section. More detailed information can be found in [25]. The prediction of damage initiation can be defined by the following constitutive equations:

Fibre tensile failure $\left(\widehat{\sigma}_{11} \geq 0\right)$ :

$$
F_{f t}=\left(\frac{\widehat{\sigma}_{11}}{X^{T}}\right)^{2}+\kappa\left(\frac{\widehat{\sigma}_{12}}{S_{12}}\right)^{2}=1
$$

Fibre compressive failure $\left(\widehat{\sigma}_{11}<0\right)$ :

$$
F_{f c}=\left(\frac{\widehat{\sigma}_{11}}{X^{C}}\right)^{2}=1
$$

Matrix tensile failure $\left(\widehat{\sigma}_{22} \geq 0\right)$ :

$$
F_{m t}=\left(\frac{\widehat{\sigma}_{22}}{Y^{T}}\right)^{2}+\left(\frac{\widehat{\sigma}_{12}}{S_{12}}\right)^{2}+\left(\frac{\widehat{\sigma}_{23}}{S_{23}}\right)^{2}=1
$$

Matrix compressive failure $\left(\widehat{\sigma}_{22}<0\right)$ :

$$
F_{m c}=\left(\frac{\sigma_{T N}}{S_{23}^{A}+\mu_{T N} \sigma_{N N}}\right)^{2}+\left(\frac{\sigma_{L N}}{S_{12}+\mu_{L N} \sigma_{N N}}\right)^{2}=1
$$

In Eqs. (3.1)-(3.4), $\widehat{\sigma}_{i j}(i, j=1,2,3)$ is the effective stress tensor where $X^{T}$ and $X^{C}$ are the tensile and compressive strengths, respectively, along the fibre direction; $Y^{T}$ represents the tensile strength in the transverse direction. $S_{12}, S_{13}$ and $S_{23}$ denote the in-plane and out-of-plane shear strengths of the composite, respectively. The contribution of the shear stress to the fibre tensile failure is defined by the coefficient $\kappa$ in Eq. (3.1), which is assumed to be equal to unity in this work. For the matrix compressive damage prediction represented by Eq. (3.4) $\widehat{\sigma}_{i j}(i, j=$ $L, T, N)$ is the stress tensor $\widehat{\sigma}_{i j}(i, j=1,2,3)$ rotated to the fracture plane by using the transformation matrix $T(\alpha)$ (shown as Eq. (3.5)). $S_{23}^{A}$ is the transverse shear strength in the fracture plane. The friction coefficients $\mu_{\mathrm{TN}}$ and $\mu_{\mathrm{LN}}$ can be defined based on the material friction angle (See refs 25, 27 for more details)

$$
\sigma_{L T N}=T(\alpha) \sigma_{123} T(\alpha)^{T}
$$


A strain-based damage variable is used to simulate the damage evolution in the composite. The typical equations defining fibre or matrix tensile damage variable are as follows:

$$
d_{1,2}^{T}=\frac{\varepsilon_{1,2}^{f T}}{\varepsilon_{1,2}^{f T}-\varepsilon_{1,2}^{0 T}}\left(1-\frac{\varepsilon_{1,2}^{0 T}}{\varepsilon_{1,2}}\right)
$$

where the subscripts 1 and 2 denote evolution prediction of fibre (parallel to fibre direction) and matrix tensile damage modes (transverse to the fibre direction), respectively; $\varepsilon_{1,2}^{0 T}$ is the tensile strain for damage initiation while $\varepsilon_{1,2}^{f T}$ denotes the tensile strain at final failure when the damage variable reaches a value of one. The final failure strain is expressed in terms of the fracture toughness $G_{1,2 C}^{T}$ associated with fibre (1) or matrix (2) tensile failure, the failure strength $\left(X^{T}\right.$ or $\left.Y^{T}\right)$ and the characteristic length, $l^{*}$ :

$$
\begin{gathered}
\varepsilon_{1}^{f T}=\frac{2 G_{1 C}^{T}}{X^{T} l^{*}} \\
\varepsilon_{2}^{f T}=\frac{2 G_{2 C}^{T}}{Y^{T} l^{*}}
\end{gathered}
$$

In addition, a semi-empirical expression is used to simulate the nonlinear shear behaviour, which has been shown to successfully predict nonlinear shear damage and induced indentation in [25], as follows:

$$
\tau_{i, j}=S_{i, j}\left[1-\exp \left(-\frac{G_{i, j}^{0} \gamma}{S_{i, j}}\right)\right], i, j=1,2,3
$$

where $\tau_{i, j}$ is the shear stress at the given shear plane, $S_{i, j}$ is the shear strength and $G_{i, j}^{0}$ is the elastic shear modulus, both of which are composite materials constants and readily measurable.

The damage initiation and evolution can be defined using the equations below [25]:

$$
\begin{gathered}
F_{i, j}^{s}=\frac{\left|\tau_{i, j}\right|}{S_{i, j}}=1, \quad i, j=1,2,3 \\
d_{i, j}=1-\frac{\gamma_{i, j, 0}-\gamma_{i, j, 0}^{i n}}{\gamma_{i, j}-\gamma_{i, j, 0}^{i n}}\left[1+\lambda^{2}(2 \lambda-3)\right] \\
\lambda=\frac{\gamma_{i, j}-\gamma_{i, j, 0}-2 \gamma_{i, j, 0}^{i n}}{\gamma_{i, j, 0}-\gamma_{i, j, 0}^{i n}-\gamma_{\mathrm{i}, \mathrm{j}}^{\mathrm{f}}}
\end{gathered}
$$

Similarly, the shear strain at complete failure can be expressed as:

$$
\gamma_{i, j}^{f}=\frac{2 G_{S}}{S_{i, j} l^{*}}
$$


where $\gamma_{i, j}^{f}$ is the shear strain at complete failure and $\gamma_{i, j, 0}$ and $\gamma_{i, j, 0}^{\text {in }}$ denote the total and inelastic strain for shear damage initiation, respectively.

\subsection{FE Modelling}

A full 3D FE model was built, including the hybrid composite plate, the impactor and two clamps as shown in Fig. 3.

As presented in section 3, two kinds of Carall structures consisting of aluminium, adhesive MTA 240 and composite layers were designed with various stacking sequences of composite layers for impact tests but keeping the same overall dimensions of $100 \times 100 \times 3.5 \mathrm{~mm}$. Global and local coordinates were defined to account for ply orientations in composite layers for the two different grades Carall 3-3/2-0.5 and Carall 5-3/2-0.5. Both clamps with an identical size of $120 \times 120 \mathrm{~mm}^{2}$ and an exposed hole of $75 \mathrm{~mm}$ in diameter in the middle were represented by shell elements. The reference point in the centre was defined and all degrees of freedom (DOFs) were fixed to constrain the composite plate. The impactor was built with a semispherical head of $15 \mathrm{~mm}$ in diameter and constrained for all DOFs except for the vertical impact direction ( $\mathrm{z}$ direction defined in Fig. 3). The impact events were simulated for two energy levels mentioned previously and a prescribed initial velocity was assigned to the impactor, consistent with the different impact heights used in the tests. Both impactor and clamps were modelled as rigid bodies. As for the FMLs, different material (aluminium, adhesive film and composites) layers were modelled using eight-node linear brick elements and only one element through the thickness was used to represent a single ply. A refined element size of $1 \times 1 \mathrm{~mm}$ was used to mesh the centre of the plate where the impacts take place while a coarser mesh was produced away from the impact area (Fig. 3), where less damage is likely to occur based on experimental observations.

The damage mechanisms in Carall are complex due to the different components of the FML and their interaction. Therefore, in order to simulate damage development in this structure, various damage models should be separately defined for the corresponding layers. Since Al 1050 was used in Carall in this work, the elastic and plastic properties, together with ductile and shear damage models, were defined by applying the data supplied in the Abaqus manual $[26,33]$, which are not listed in this paper due to a large amount of parameters (refer to [26] for details). It is worth noting that these damage properties may slightly differ from those of $\mathrm{Al}$ 1050 investigated in this work. The ductile and shear damage modes are activated based on the fracture strain values measured experimentally [26], and an element deletion procedure is then used once the damage variable for the metal fracture model has reached a value of one.

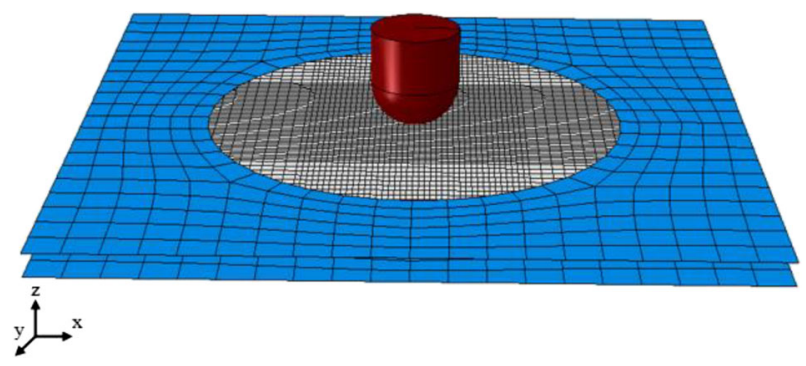

Fig. 3 FE model of CARALL for the numerical simulation of the impact event 
The detailed material properties for the composite layers are listed in Table 1 [25] and the user subroutine VUMAT was used to implement the models for different damage modes in composites layers using energy based damage evolution laws. Cohesive zone elements, $\mathrm{COH} 3 \mathrm{D} 8$, were inserted within composite layers and at interfaces between metal and adhesive layers for modelling delamination and debonding (See Fig. 4). The properties assigned to the cohesive elements are defined with different fracture toughness values related to the interfaces modelled, as listed in Table $2[27,34]$. The stiffness value for cohesive elements layers located in the composite was selected as $10^{6} \mathrm{~N} / \mathrm{mm}^{3}$ [27-29]. Damage evolution for cohesive zone elements was predicted using the Benzeggagh-Kenane fracture energy law which accounts for the mixed mode effect of the three damage modes with factor $\eta=1.45$ experimentally obtained for carbon fibre composite laminates [27].

In addition, for adhesive layers between aluminium and composite layers, only elastic properties have been defined by reference to the datasheet from Advanced composite group Ltd. (ACG) [34] without any damage criteria applied.

Contact between the impactor and composite plates and between both clamps and composites has been defined by the general contact algorithm within Abaqus/Explicit and a consistent friction coefficient value of $\mu=0.3$ was used [25]. In order to avoid unreasonable penetration within the composite plates, contacts were also assigned at each interface between two adjacent composite layers. A friction coefficient of 0.5 was used at the $0^{\circ} / 90^{\circ}$ interfaces of the composite layers [35-37] and at the interfaces between adhesive and composite layers while a value of 0.3 was defined for the contact pair of aluminium and adhesive layers.

\section{Results and Discussions}

\subsection{Impact Force and Energy}

Figure 5 shows the impact force-time histories for the two grades of Carall and for two selected impact energy levels. It can be seen that during the initial phase the force-time curves for both structures are superimposed with some slight oscillations occurring from approximately $0.1 \mathrm{~ms}$. This could be mainly attributed to elastic vibration generated when the impactor initially contacts the composite plate. As further contact between the impactor and the composite plate takes place, the force increases up to a peak value. More intense oscillations can be observed in the peak force region as the impact energy increases due to internal damage produced within the composite plates. In addition, it can be observed that the load decreases faster during the rebound phase for Carall 5-3/2-0.5 than for Carall 3-3/2-0.5, which is more obvious for higher impact energies.

Table 1 Material properties of the carbon fibre/epoxy unidirectional laminate [25]

\begin{tabular}{ll}
\hline Density $\left(\mathrm{kg} / \mathrm{m}^{3}\right)$ & 1600 \\
\hline Orthotropic properties & $E_{1}^{0}=153 G P a ; E_{2}^{0}=E_{3}^{0}=10.3 G P a ; v_{12}=v_{13}=0.3 ;$ \\
& $v_{23}=0.4 ; G_{12}^{0}=G_{13}^{0}=6 G P a ; G_{23}^{0}=3.7 G P a$ \\
& $X^{T}=2537 ; X^{C}=1580 ; Y^{T}=82 ; Y^{C}=236 ; S_{12}=90 ; S_{23}=40$ \\
$\begin{array}{l}\text { Strength }(\mathrm{MPa}) \\
\begin{array}{l}\text { In-plane fracture toughness } \\
\left(\mathrm{kJ} / \mathrm{m}^{2}\right)\end{array}\end{array}$ \\
\hline
\end{tabular}




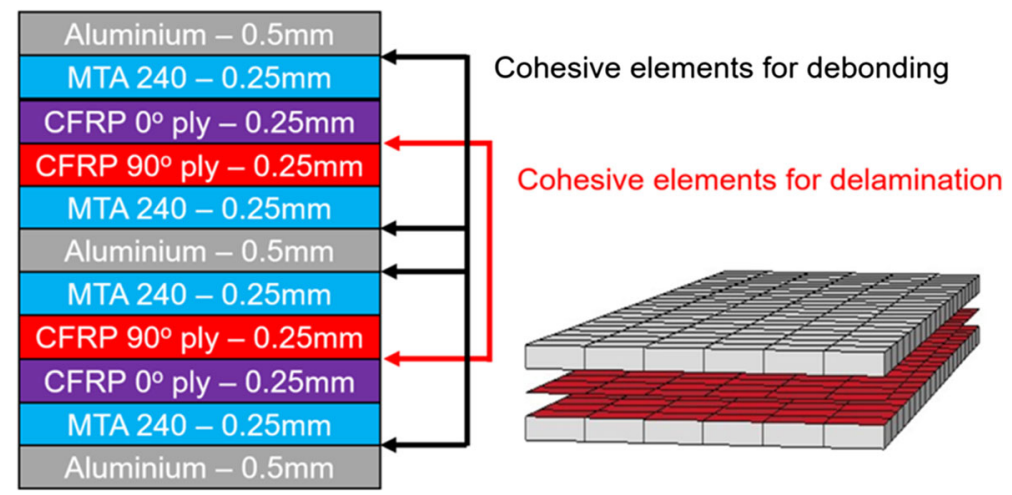

Fig. 4 A schematic of cohesive zone elements inserted in the Carall model

For the impact energy of 9.8 J, Fig. 5(a) shows that the force-time history curves for Carall $3-3 / 2-0.5$ and Carall 5-3/2-0.5 are similar, although the maximum force for Carall 5-3/2-0.5 $(4215 \mathrm{~N})$ is slightly higher than that of Carall 3-3/2-0.5 $(3985 \mathrm{~N})$. This difference of peak force value between two grades of Carall is considerably increased when the impact energy is $29.4 \mathrm{~J}$ where the maximum impact force for Carall $5-3 / 2-0.5(6308 \mathrm{~N})$ is $709 \mathrm{~N}$ higher than that for Carall 3-3/2-0.5 (5599 N).

The impact energies for both hybrid plates are found to be identical in the initial phase as the absorbed energy increases (Fig. 6). Then the energy increases faster for Carall 5-3/2-0.5 until it reaches a maximum value earlier than for Carall 3-3/2-0.5 for every impact energy level. This is in accordance with the impact force data for which the peak forces for Carall 5-3/2-0.5 are always higher than those for Carall 3$3 / 2-0.5$, with a difference which becomes more noticeable for the higher impact energy level, as shown in Fig. 5(b). The energy eventually absorbed by Carall 3-3/ $2-0.5$ is found to be always higher than that for Carall $5-3 / 2-0.5$ in Fig. 6, with detailed values listed in Table 3. This result indicates that more internal damage or permanent deformation have been produced for Carall 3-3/2-0.5.

The experimentally measured and numerically predicted impact force and energy curves for Carall 3-3/2-0.5 and Carall 5-3/2-0.5 are shown in Figs. 7 and 8, respectively, for different impact energy levels. The FE model gives a good prediction of impact force compared to the experimental measurement, although the predicted maximum force is always higher than that of the experiment for two impact energy cases. As for the impact energy, it can be seen from Figs. 7 and 8 that the total

Table 2 Material parameters used for the interface cohesive elements [27, 34]

\begin{tabular}{llll}
\hline Interface within composite layers & Mode I & Mode II & Mode III \\
\hline Normalised elastic modulus $(\mathrm{GPa} / \mathrm{mm})$ & $10^{6}$ & $10^{6}$ & $10^{6}$ \\
Inter-laminar strength $(\mathrm{MPa})$ & 62.3 & 92.3 & 92.3 \\
Inter-laminar fracture toughness $\left(\mathrm{J} / \mathrm{m}^{2}\right)$ & 280 & 790 & 790 \\
Interface between Al and adhesive layers & Mode I & Mode II & Mode III \\
Normalised elastic modulus $(\mathrm{GPa} / \mathrm{mm})$ & $10^{6}$ & $10^{6}$ & $10^{6}$ \\
Inter-laminar strength $(\mathrm{MPa})$ & 30 & 40 & 40 \\
Inter-laminar fracture toughness $\left(\mathrm{J} / \mathrm{m}^{2}\right)$ & 600 & 1800 & 1800 \\
\hline
\end{tabular}




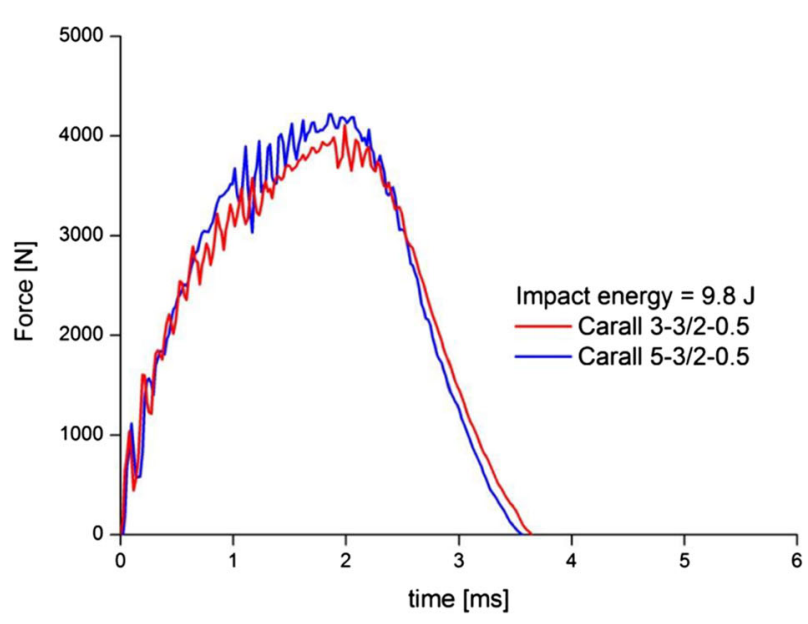

(a)

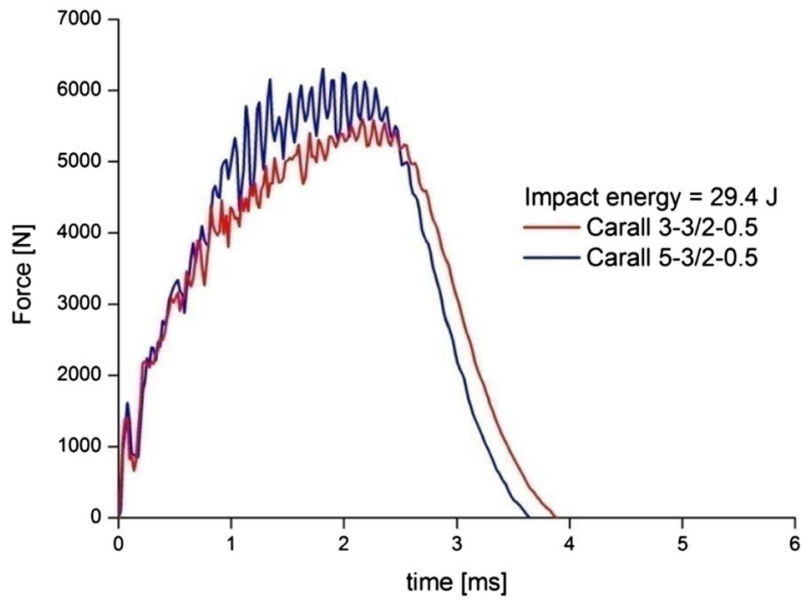

(b)

Fig. 5 Impact force-time histories for Carall 3-3/2-0.5 and Carall 5-3/2-0.5: a Impact energy of 9.8 J; b Impact energy of $29.4 \mathrm{~J}$

absorbed energy is under-predicted by the FE model, which is most likely due to the lack of damage prediction in the bottom aluminium ply and cracks in adhesive layers that have been observed using a non-destructive technique (presented in following section). The predicted maximum impact force and absorbed energy values are listed in Table 3 in comparison with experimental data. The results show that the difference between experimental and numerical values is generally reduced with an increase in impact energy. This indicates that the developed model is more performant in simulating the impact behaviour and damage development for higher impact energy levels since more severe damage and deformation are generated. However, it is worth noting that the difference between numerical and experimental values of absorbed energy in Table 3 for Carall 5-3/2-0.5 and for an impact energy of $29.4 \mathrm{~J}$ is reversely increased. For that material and impact energy level, Fig. $8 \mathrm{c}$ shows a higher peak 


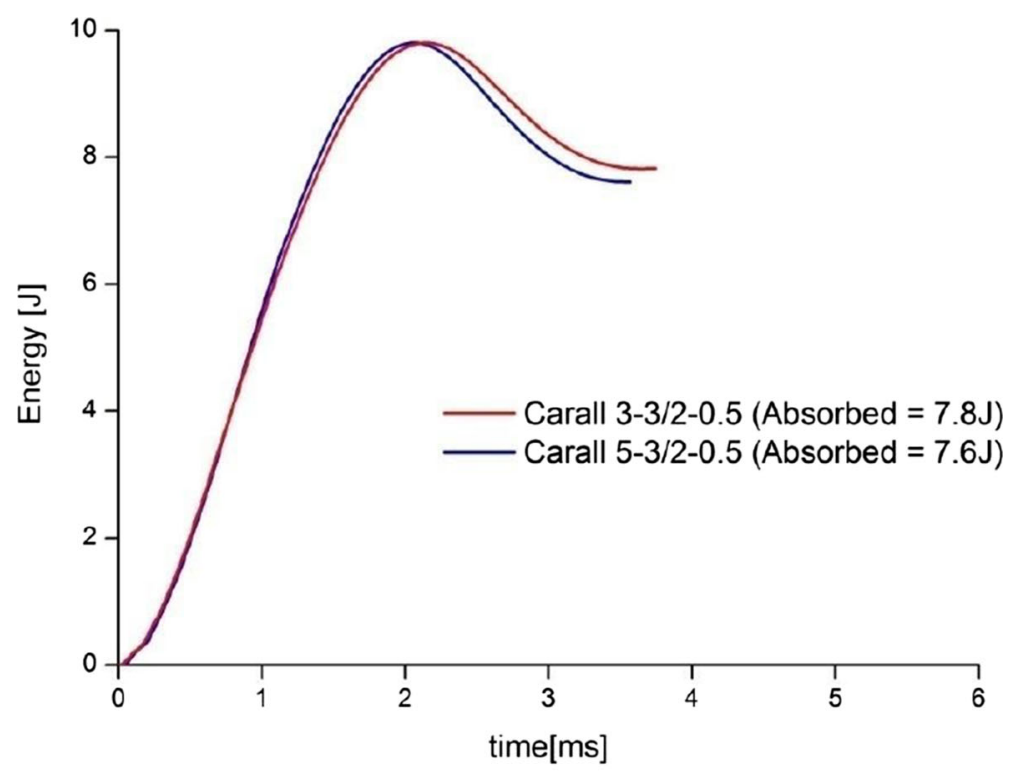

(a)

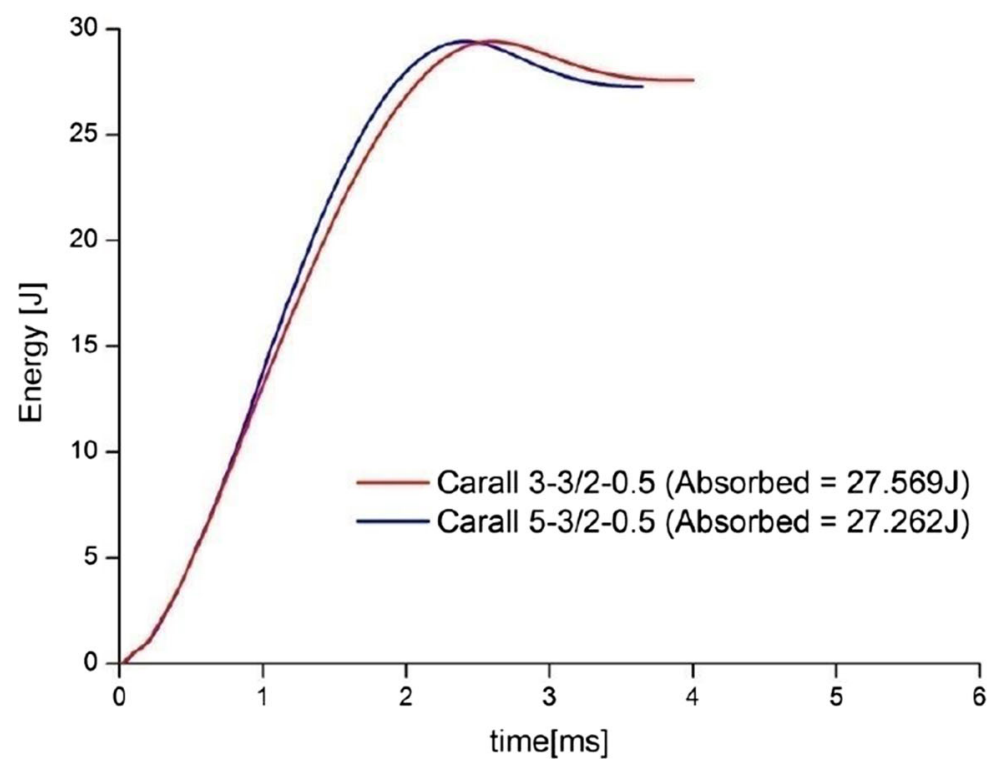

(b)

Fig. 6 Impact energy-time histories for Carall 3-3/2-0.5 and Carall 5-3/2-0.5: a Impact energy of $9.8 \mathrm{~J}$; b Impact energy of $29.4 \mathrm{~J}$

force and faster rebound phase predicted by the FE model in comparison with the experimental result. This is most likely due to the FE model under-predicting splitting in composite, damage in the adhesive and aluminium layers as well as at their interfaces. 
Table 3 Experimental and numerical values of maximum impact force and absorbed energies

\begin{tabular}{|c|c|c|c|c|c|}
\hline \multicolumn{2}{|c|}{ Impact energy $(\mathrm{J})$} & \multicolumn{2}{|l|}{ Carall 3-3/2-0.5 } & \multicolumn{2}{|l|}{ Carall 5-3/2-0.5 } \\
\hline & & Maximum Force $(\mathrm{N})$ & Absorbed energy $(\mathrm{J})$ & Maximum Force $(\mathrm{N})$ & Absorbed energy $(\mathrm{J})$ \\
\hline \multirow[t]{3}{*}{9.8} & Simulation & 4464.1 & 6.59 & 4630.3 & 6.8 \\
\hline & Experiment & 3985 & 7.8 & 4215 & 7.6 \\
\hline & Difference $(\%)$ & 12 & 15.5 & 9.8 & 10.5 \\
\hline \multirow[t]{3}{*}{29.4} & Simulation & 5965.8 & 25.2 & 6879.7 & 23.56 \\
\hline & Experiment & 5599 & 27.57 & 6308 & 27.26 \\
\hline & Difference (\%) & 6.5 & 8.6 & 9 & 13.5 \\
\hline
\end{tabular}

\subsection{Impact Induced Damage}

Results of impact-induced damage measured using C-Scan and X-RCT techniques are reported in this section and used to evaluate the prediction from the FE model at different scales.

Figure 9 shows the numerically modelled damage extent for Carall 3-3/2-0.5 for two impact energy levels in comparison with experimental measurements obtained using ultrasonic

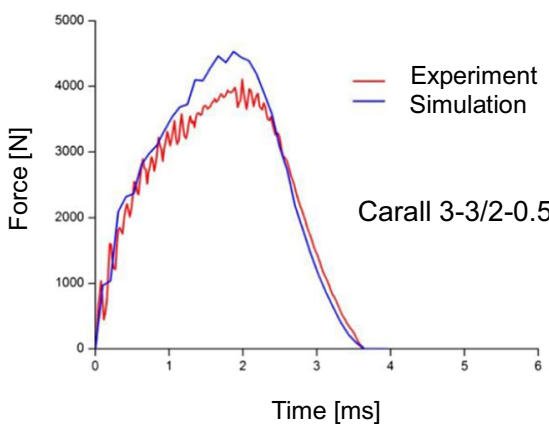

(a)

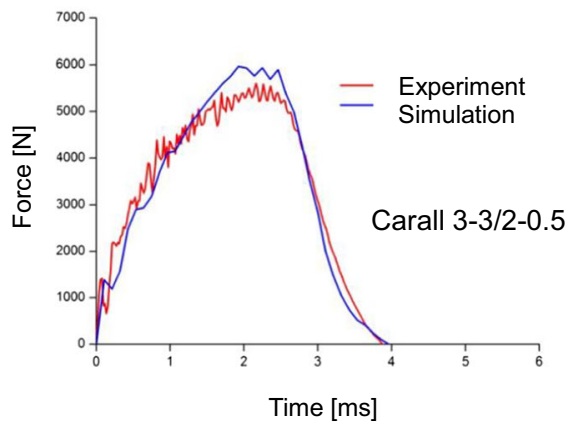

(c)

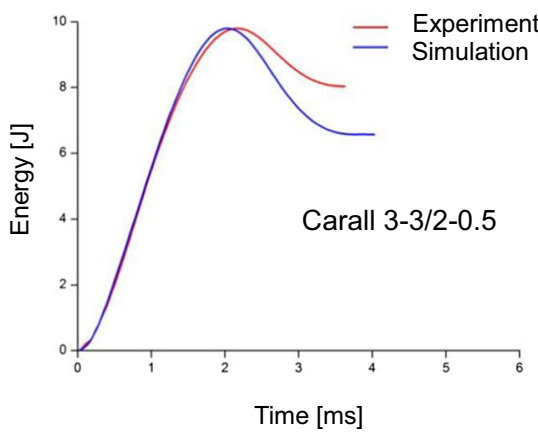

(b)

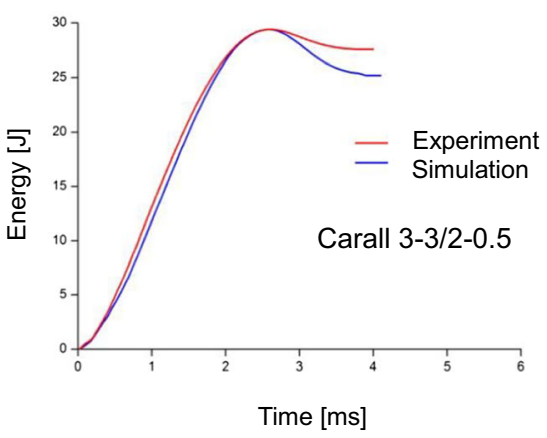

(d)

Fig. 7 Experimental and numerically predicted results for Carall 3-3/2-0.5: a-b Impact energy of $9.8 \mathrm{~J}$; c-d Impact energy of $29.4 \mathrm{~J}$ 


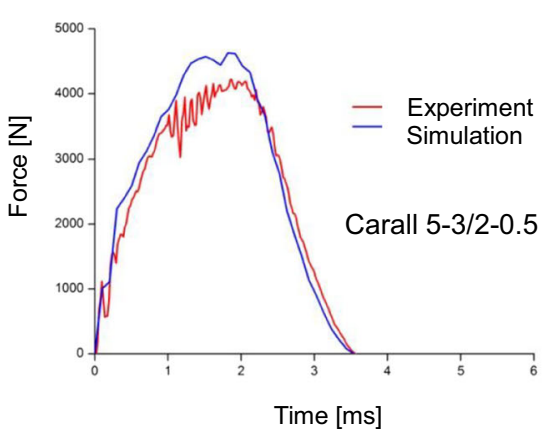

(a)

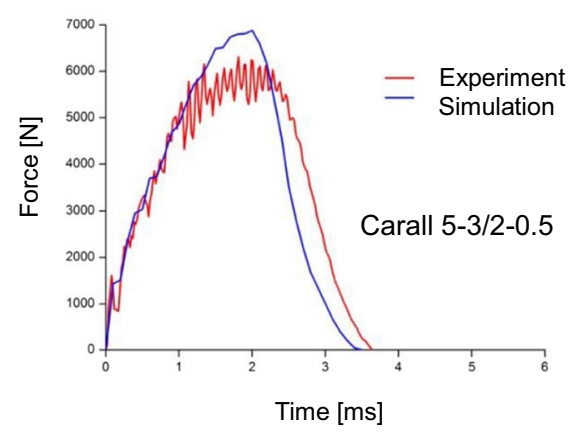

(c)

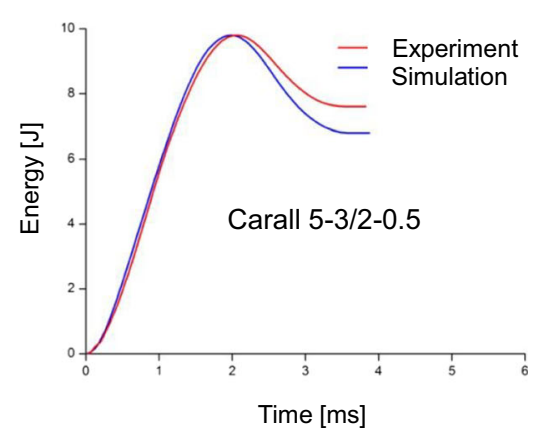

(b)

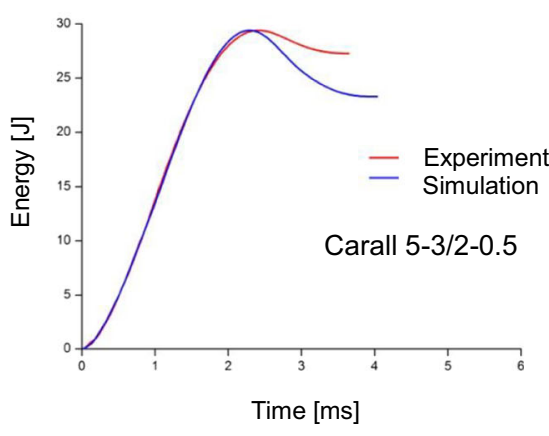

(d)

Fig. 8 Experimental and numerically predicted results for Carall 5-3/2-0.5: a-b Impact energy of 9.8 J; c-d Impact energy of $29.4 \mathrm{~J}$

C-Scan. The peanut-like shape of the damage area is correctly simulated by the FE model, especially for the relatively low impact energy, although the predicted damage area is a little larger than the measured area for both impact energy levels. This could be due to the material properties introduced through damage parameters in the FE model which may differ from real values, therefore leading to an over-prediction of damage in composite layers compared to experimental results. In Fig. 9d, the boundaries of the predicted damage area are not as smooth as for the lower impact energy levels. This is likely due to the coarser mesh applied away from the central impacted area to minimise computing time.

The damage extent predicted by the FE model for Carall 5-3/2-0.5 is similarly compared to that measured by C-Scan in Fig. 10. The elliptical-shaped damage area is reasonably well simulated, although its size is slightly over-predicted due to the potentially inaccurate material properties introduced in the model. In particular, the difference is increased for the impact energy of $29.4 \mathrm{~J}$ for which splitting occurring in the bottom $0^{\circ}$ ply is not considered by the FE model.

In Fig. 11a matrix cracking in $90^{\circ}$ plies located above and below the middle aluminium layer of Carall 3-3/2-0.5 can be observed. Cracks appear to propagate from the carbon-fibre composite layer to the interface of adhesive layer due to its strong adhesion. A large amount of delamination at the interface between the $90^{\circ}$ and $0^{\circ}$ plies located closely to the non-impacted 


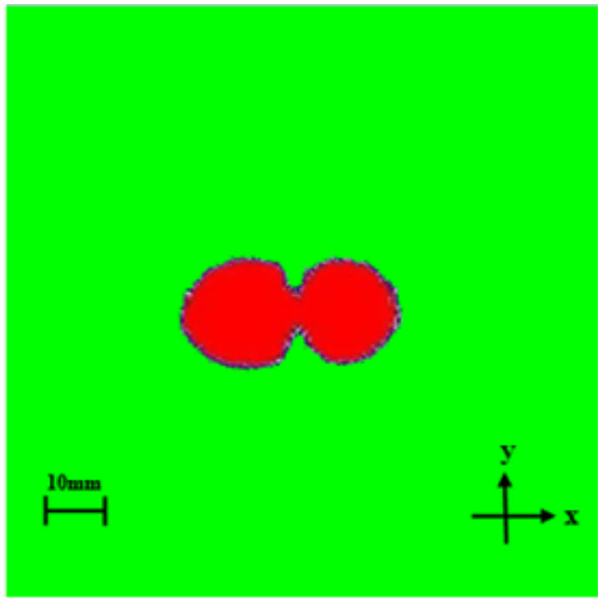

(a)

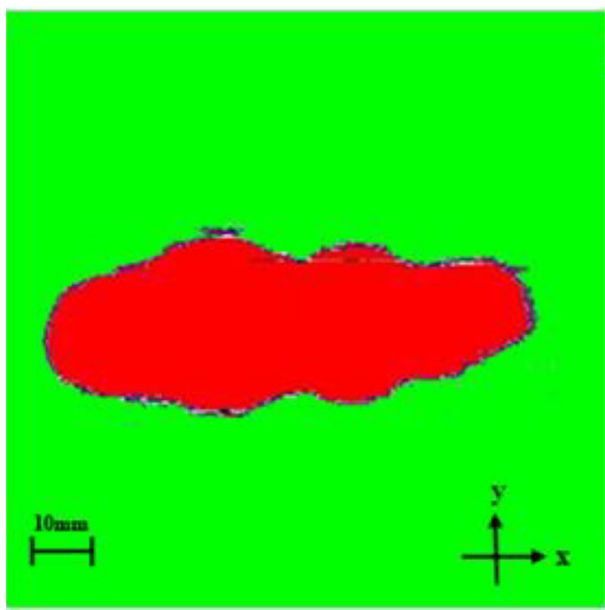

(c)

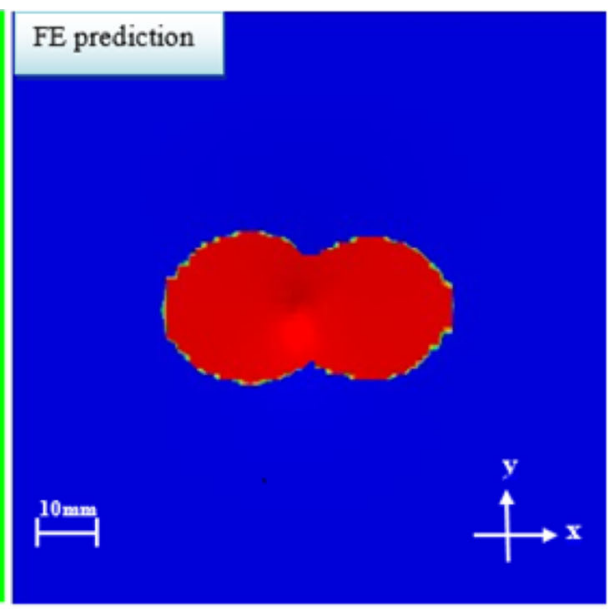

(b)

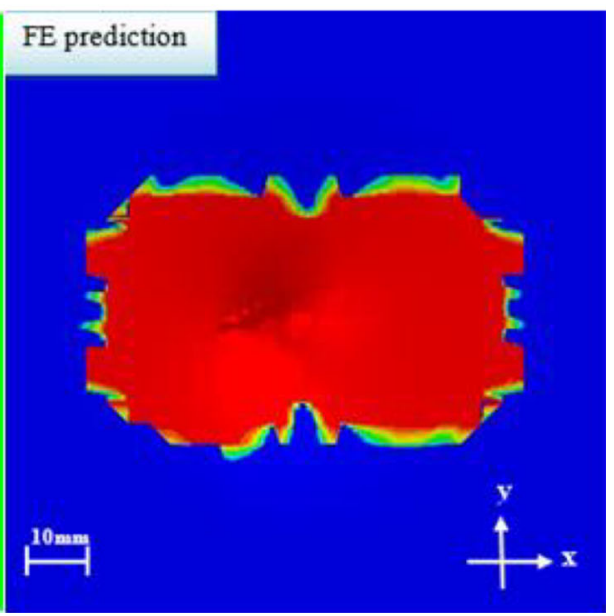

(d)

Fig. 9 Ultrasonic C-Scan and numerically predicted overall damage area for Carall 3-3/2-0.5: a-b Impact energy of $9.8 \mathrm{~J}$; c-d Impact energy of $29.4 \mathrm{~J}$

side is clearly visible, while debonding at the interface between aluminium and adhesive layers is rarely detected at the $9.8 \mathrm{~J}$ impact energy level. Similarly, the impact-induced damage for Carall 5-3/2-0.5 is successfully captured in Fig. $11 \mathrm{~b}$ with matrix cracks also clearly visible in each single lamina that is bonded to the aluminium, below the middle aluminium ply, with propagation through the thickness of the adhesive film. However, the matrix crack size is smaller than that in Carall 3-3/2-0.5 due to smaller thickness of each lamina of carbon fibre/ epoxy in Carall 5-3/2-0.5. Moreover, cracks are not found in the carbon fibre epoxy layers located above the middle aluminium ply. As expected, delamination can be found at two interfaces where neighbouring plies were laid up with various stacking sequences for the carbon fibre/epoxy layers below the middle aluminium ply. However, the length and extent of delamination found at each interface is obviously smaller than that observed for Carall 3-3/2- 


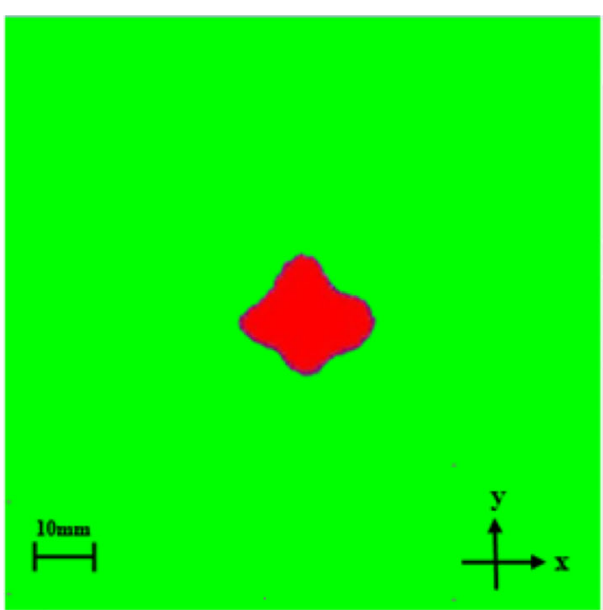

(a)

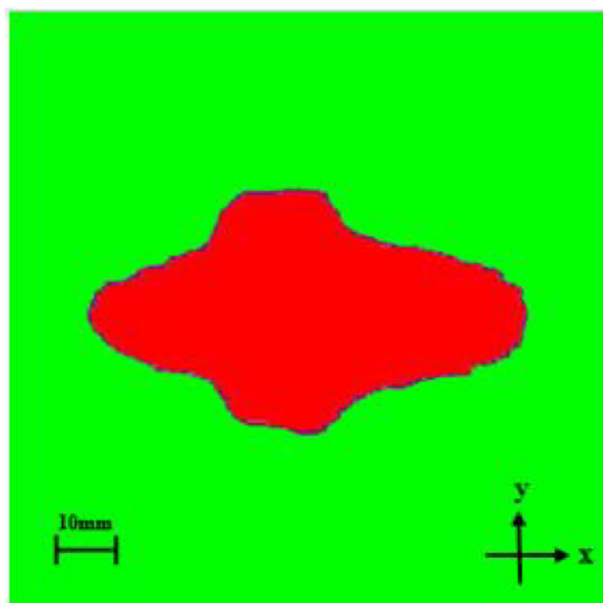

(c)

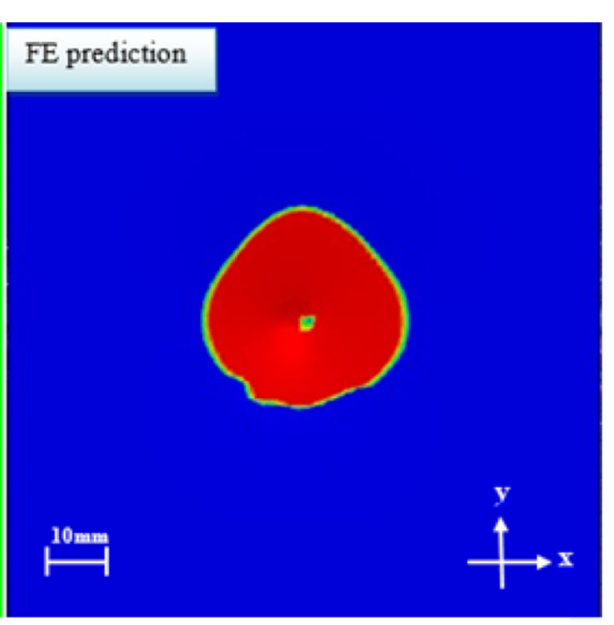

(b)

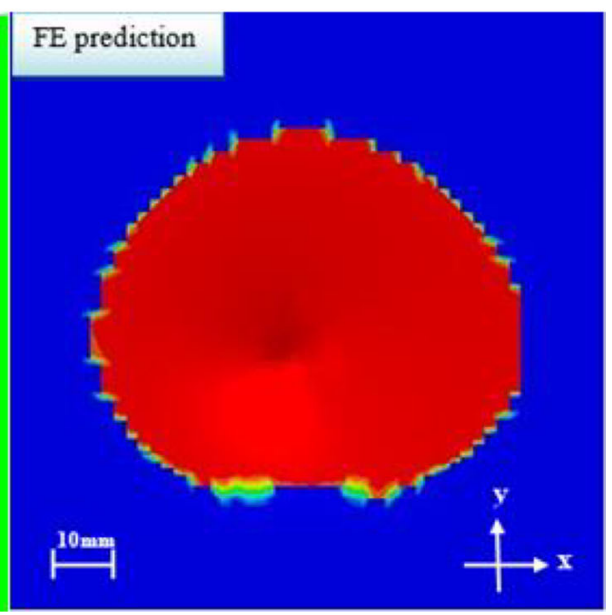

(d)

Fig. 10 Ultrasonic C-Scan and numerically predicted overall damage area for Carall 5-3/2-0.5: a-b Impact energy of $9.8 \mathrm{~J}$; c-d Impact energy of $29.4 \mathrm{~J}$

0.5 (see Fig. 11a). Debonding at the interface between aluminium and adhesive layers is not observed at all, even though cracks have propagated to the interface.

The different delamination extents in these two structures can be due to the larger number of interfaces available in the carbon fibre/epoxy lay-up of Carall 5-3/2-0.5 to absorb and share the impact energy through delamination whereas only one interface can be used in Carall 3-3/ $2-0.5$ to absorb the same amount of energy. A longer delamination extent with a bigger opening of the interface crack is hence observed for Carall 3-3/2-0.5 in Fig. 11a. This is consistent with the results obtained using C-Scan with a larger damage area revealed for Carall $3-3 / 2-0.5$. Therefore, results obtained with the X-RCT technique confirm that the structure of Carall 5-3/2-0.5 offers better impact resistance with less damage formed internally. 

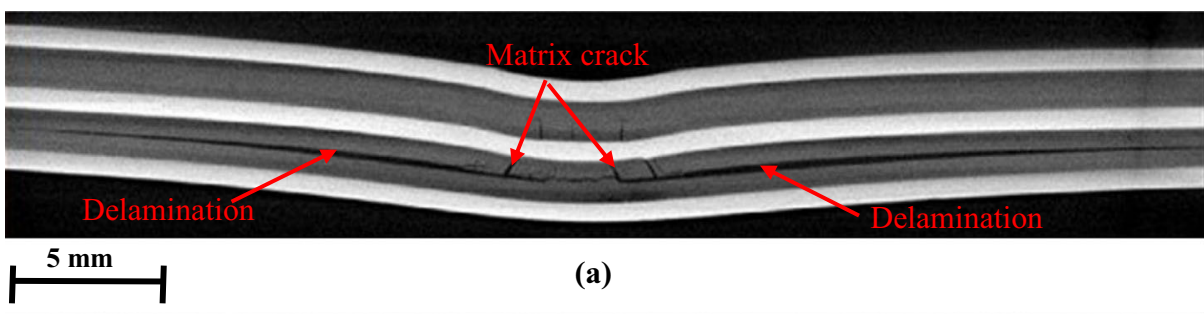

(a)
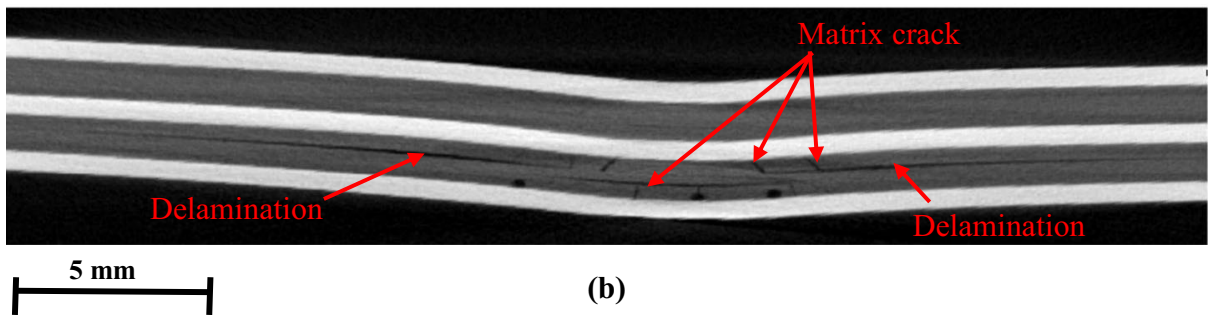

(b)

Fig. 11 Section view of damage modes detected by X-RCT for an impact energy of $9.8 \mathrm{~J}$ : a Carall 3-3/2-0.5 b Carall 5-3/2-0.5

In Figs. 12 and 13, damage prediction from the FE model is compared to experimental measurements using X-RCT scan. In Fig. 12, the FE model similarly predicts the delamination extent at the same $90 \% 0^{\circ}$ interface as in the experiment, within the composite layers of Carall $3-3 / 2-0.5$, below the middle aluminium layer, for an impact energy of $9.8 \mathrm{~J}$. A smaller delamination is also predicted by the numerical model at interfaces of carbon fibre/epoxy layers above the middle aluminium layer, which does not appear clearly in the X-RCT scanned image. While delamination might not have taken place at this location in the experiment, it is also possible that it has not been revealed due to the resolution limit of the X-RCT scan technique.

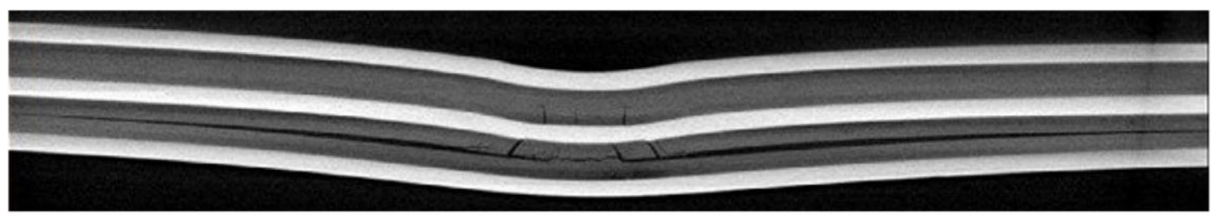

a X-RCT

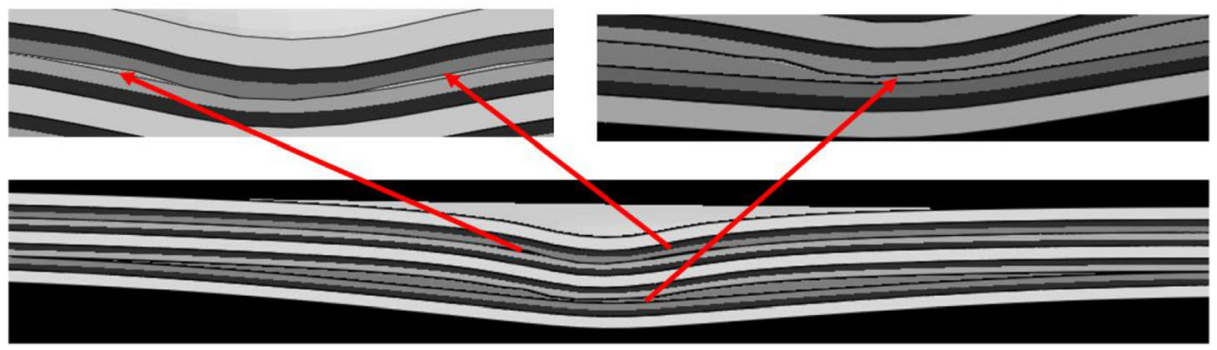

b Simulation

Fig. 12 Experimental and numerically predicted damage through the thickness of the Carall 3-3/2-0.5 laminate for an impact energy of $9.8 \mathrm{~J}$ : a X-RCT scan b Simulation 


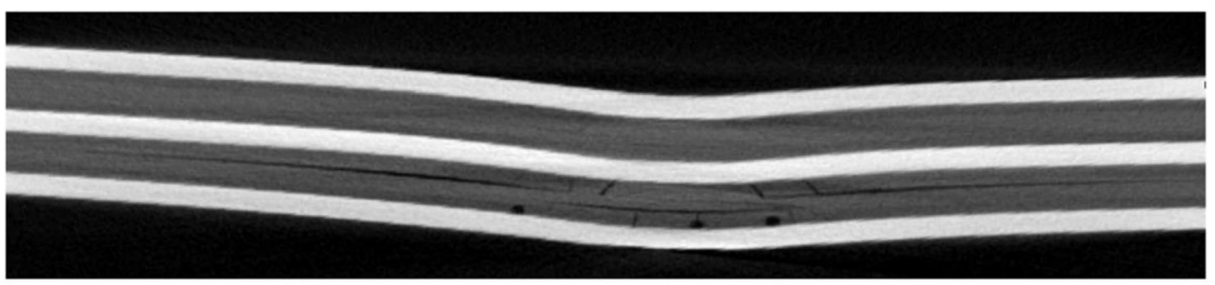

a X-RCT

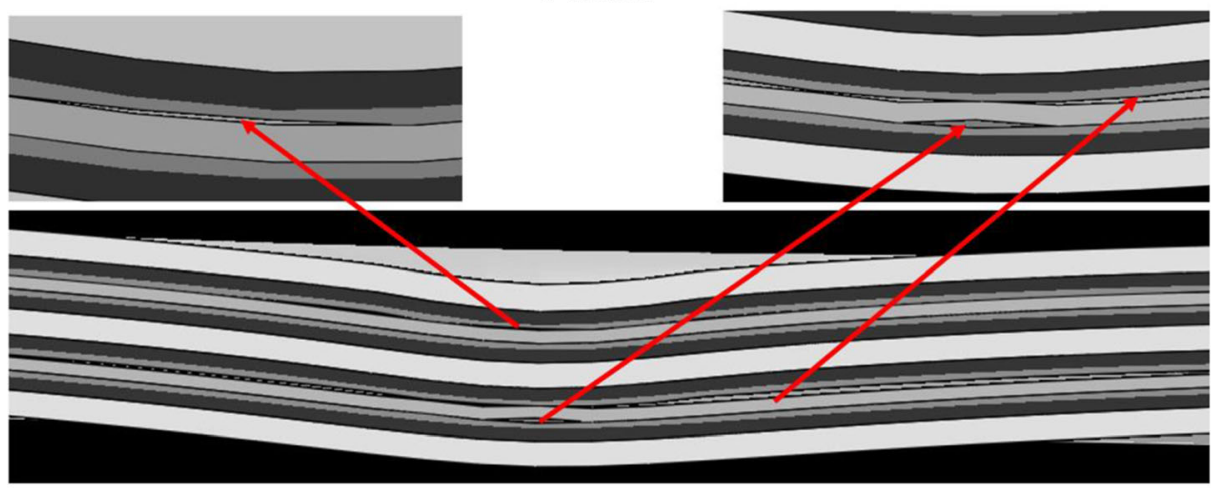

b Simulation

Fig. 13 Experimental and numerically predicted damage through the thickness of the Carall 5-3/2-0.5 laminate for an impact energy of $9.8 \mathrm{~J}$ : a X-RCT scan b Simulation

The impact induced damage in Carall $5-3 / 2-0.5$ is shown in Fig. 13 with a comparison between the experimental X-RCT scan measurement and numerical prediction for an impact energy of $9.8 \mathrm{~J}$. In Fig. 13, delamination in the FE model is successfully predicted at both the $0^{\circ} / 90^{\circ}$ and $90^{\circ} / 0^{\circ}$ interfaces of the composite plies close to the non-impacted side, which is consistent with the X-RCT result. Similarly to Carall 3-3/2-0.5, delamination at the $0^{\circ} / 90^{\circ}$ interface in the composite above the middle aluminium layer is also observed in the FE model. This, again, might be related to an inaccuracy in the modelling prediction or to a resolution limit with experimental X-RCT scans. Debonding at the interface between aluminium and adhesive layers is not observed in both experimental and numerical results, even though cracks are found to propagate at the interface in the experiment.

The impact-induced deformation and damage in the aluminium layer located on the non-impacted side of the two hybrid composite structures is shown in Fig. 14 for two impact energies. In Fig. 14a no cracks are found for both Carall 3-3/2-0.5 and Carall 5$3 / 2-0.5$ for the lower impact energy. However, with the increase in impact energy (29.4 J in Fig. 14b), it can be seen that the delaminated area represented by the region of a dark shade in Carall 3-3/2-0.5 is only elongated along the fibre direction of the $0^{\circ}$ ply, while it grows along both the $0^{\circ}$ and $90^{\circ}$ directions in Carall 5-3/2-0.5. These results are therefore consistent with the non-destructive testing results obtained using C-Scan. The crack length in the bottom aluminium layer and the depth of permanent indentation created on the impacted face are listed in Table 4 for all tests carried out. Cracks in the aluminium layer at the non-impacted side of the specimen have been found in both 

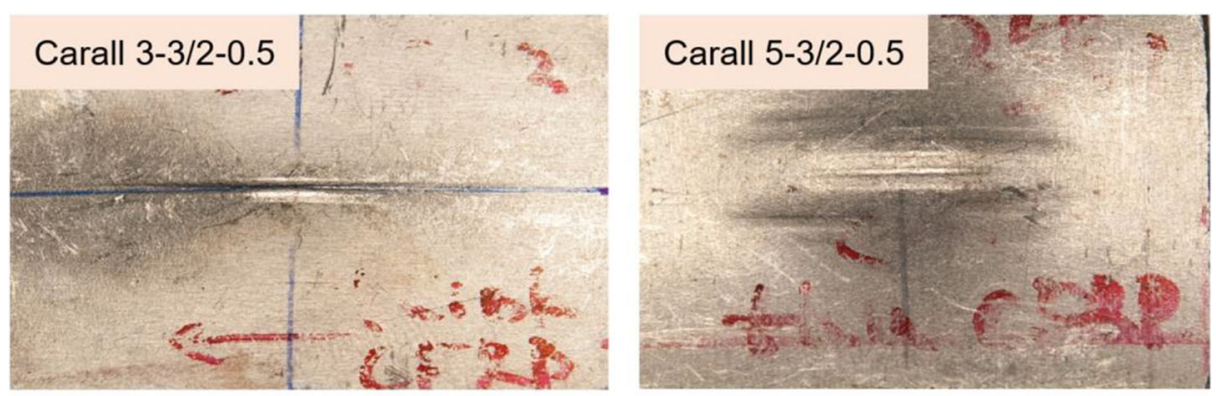

a $9.8 \mathrm{~J}$
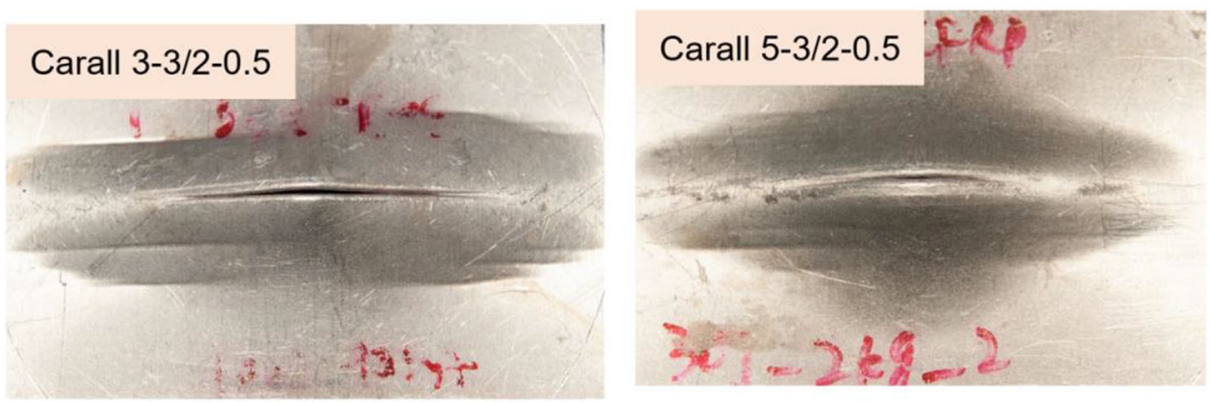

b $29.4 \mathrm{~J}$

Fig. 14 Impact induced damage of the non-impacted side in Carall 3-3/2-0.5 and Carall 5-3/2-0.5 for various impact energies: a $9.8 \mathrm{~J} ; \mathbf{b} 29.4 \mathrm{~J}$

structures for an impact energy of $29.4 \mathrm{~J}$. However, the crack length in Carall 3-3/2-0.5 is longer than that in Carall 5-3/2-0.5 along the fibre direction of the $0^{\circ} \mathrm{ply}$. This can be explained by the fact that, compared to Carall 5-3/2-0.5, the layup of the carbon fibre/ epoxy layers in Carall 3-3/2-0.5 has lower transverse bending stiffness leading to higher deformation in the transverse direction with, eventually, cracks forming along the $0^{\circ}$ fibre direction once the applied impact load is high enough.

\section{Concluding Remarks}

In this paper, the low velocity impact behaviour and impact induced damage of hybrid composite Carbon/aluminium laminates (Carall) were experimentally studied for two grades (Carall 3-3/2-0.5 and Carall 5-3/2-0.5), which have the same structure apart from the stacking sequence of the composite layers. A finite element model was developed to simulate

Table 4 Crack length in non-impacted aluminium layer and permanent indentation in both hybrid composite structures for different impact energies

\begin{tabular}{llllll}
\hline Impact energy $(\mathrm{J})$ & \multicolumn{2}{l}{ Crack length in bottom Al layer $(\mathrm{mm})$} & & \multicolumn{2}{l}{ Permanent indentation (mm) } \\
\cline { 2 - 3 } & Carall 3-3/2-0.5 & Carall 5-3/2-0.5 & & Carall 3-3/2-0.5 & Carall 5-3/2-0.5 \\
\hline 9.8 & 0 & 0 & & 0.83 & 0.69 \\
29.4 & 23 & 7 & 2.5 & 2 \\
\hline
\end{tabular}


various damage modes and their interaction in Carall for two impact energies of $9.8 \mathrm{~J}$ and $29.4 \mathrm{~J}$.

For these two energies, a slight difference, in terms of impact force and energy- time histories, was only observed between the two laminate configurations. Carall 3-3/2-0.5 absorbed more energy than Carall 5-3/2-0.5 indicating that a higher number of composite plies inserted between aluminium layers could reduce the extent of damage with smaller cracks shared by the higher number of interfaces and therefore can offer a better impact resistance. Simulation results showed reasonably accurate predictions of impact force-time and energytime histories, while the absorbed energy was slightly under-predicted (within 15\% maximum shown in Table 3). The difference between FE simulations and experimental measurements are attributed to (i) the relatively coarse mesh used in the simulations, (ii) possibly inaccurate material properties and damage model of aluminium layer and (iii) lack of a damage model for the adhesive layers, which was not considered in this work.

In addition, the crack in the aluminium layer was found along the fibre direction of the $0^{\circ}$ ply of the carbon fibre/epoxy layer at various impact energy levels. This has been attributed to a lower transverse bending stiffness for Carall 3-3/2-0.5, directly resulting from the stacking sequence of [0/90] carbon fibre/epoxy layers compared to Carall 5-3/2-0.5. This evidence further supports the conclusion that Carall 5-3/2-0.5 exhibits a better impact resistance than Carall 3-3/2-0.5. Both experimental and numerical modelling results therefore provide new insight to effectively help composite engineers design and select appropriate fibre metal laminates for aircraft structures, vulnerable to external impact.

Open Access This article is licensed under a Creative Commons Attribution 4.0 International License, which permits use, sharing, adaptation, distribution and reproduction in any medium or format, as long as you give appropriate credit to the original author(s) and the source, provide a link to the Creative Commons licence, and indicate if changes were made. The images or other third party material in this article are included in the article's Creative Commons licence, unless indicated otherwise in a credit line to the material. If material is not included in the article's Creative Commons licence and your intended use is not permitted by statutory regulation or exceeds the permitted use, you will need to obtain permission directly from the copyright holder. To view a copy of this licence, visit http://creativecommons.org/licenses/by/4.0/.

\section{References}

1. Vlot, A.D., Gunnink, J.W.: Fibre Metal Laminates: an Introduction. Kluwer Academic Publisher, The Netherlands (2001)

2. Sinmazçelik, T., Avcu, E., Bora, M.Ö., Çoban, O.: A review: fibre metal laminates, background, bonding types and applied test methods. Mater. Des. 32, 3671-3685 (2011)

3. van Tooren, MJL, Sinke, J, Bersee, HEN. Composites: Materials, Structures \& Manufacturing Process. Dictaat 32, Delft, The Netherlands, 1993

4. Moussavi-Torshizi, S.E., Dariushic, S., Sadighic, M., Safarpour, P.: A study on tensile properties of a novel fiber/metal laminates. Mater. Sci. Eng. A. 527, 4920-4925 (2010)

5. Lin, C.T., Kao, P.W.: Fatigue delamination growth in carbon fibre-reinforced aluminium laminates. Composites A. 27A, 9-15 (1996)

6. Xia, Y., Wang, Y., Zhou, Y., Jeelani, S.: Effect of strain rate on tensile behavior of carbon fiber reinforced aluminum laminates. Mater. Lett. 61, 213-215 (2007)

7. Lin, C.T., Kao, P.W., Yang, F.S.: Fatigue behaviour of carbon fibre-reinforced aluminium laminates. Composites. 22(2), 135-141 (1991)

8. Khalili, S.M.R., Mittal, R.K., Gharibi Kalibar, S.: A study of the mechanical properties of steel/aluminium/ GRP laminates. Mat Sic Eng A. 412, 137-140 (2005)

9. Carrillo, J.G., Cantwell, W.J.: Mechanical properties of a novel fiber-metal laminate based on a polypropylene composite. Mech. Mater. 41, 828-838 (2009) 
10. Lawcock, G., Ye, L., Mai, Y.W., Sun, C.T.: The effect of adhesive bonding between alumium and composite prepreg on the mechanical properties of carbon-fibre-reinforced metal laminates. Compos. Sci. Technol. 57, 35-45 (1997)

11. Reyes, G., Kang, H.: Mechanical behavior of lightweight thermoplastic Fiber-metal laminates. J. Mater. Process. Technol. 186, 284-290 (2007)

12. Vermeeren, CAJR. The application of carbon fibres in Arall Laminates. Report LR 658, Delft, The Netherlands, 1991

13. Starikov, R.: Assessment of impact response of fiber metal laminates. Int J Impact Eng. 59, 38-45 (2013)

14. Vlot, A.: Impact properties of fibre metal laminates. Compos. Eng. 10(3), 911-927 (1993)

15. Vlot, A.: Impact loading on fibre metal laminates. Int J Impact Eng. 18, 291-307 (1996)

16. Caprinoa, G., Spatarob, G., Del Luongo, S.: Low-velocity impact behaviour of fibreglass-aluminium laminates. Compos. Part A: Appl. Sci. Manuf. 35, 605-616 (2004)

17. Laliberté, J.F., Poon, C., Straznicky, P.V.: Low velocity impact damage in GLARE@ fibre metal laminates. In: Massard, T. (ed.) Proceedings of the 12th international conference on composite materials. ICCM12, Paris (1999)

18. Laliberté, J.F., Poon, C., Straznicky, P.V., Fahr, A.: Post-impact fatigue damage growth in fiber-metal laminates. Int. J. Fatigue. 24, 249-256 (2002)

19. Starikov, R.: Fatigue resistance of composite fiber metal laminates subjected to impact loading. In: Asp, L. (ed.) Proceedings of the 13th European conference on composite materials. ECCM-13, Stockholm (2008)

20. Seyed Yaghoubi, A., Liu, Y., Liaw, B.: Stacking sequence and geometrical effects on low-velocity impact behaviours of GLARE 5 (3/2) fibre-metal laminates. J. Thermoplast. Compos. 25, 223-247 (2012)

21. Vlot, A. Low velocity impact loading on fibre reinforced aluminium laminates (ARALL) and other aircraft sheet materials. Dissertation. Delft University of Technology, 1991

22. Nakatani, H., Kosaka, T., Osaka, K., Sawada, Y.: Damage characterization of titanium/GFRP hybrid laminates subjected to low-velocity impact. Compos. Part A: Appl. Sci. Manuf. 42, 772-781 (2011)

23. Sadighi, M., Pärnänen, T., Alderliesten, R.C., Sayeaftabi, M., Benedictus, R.: Experimental and numerical investigation of metal type and thickness effects on the impact resistance of fibre metal laminates. Appl. Compos. Mater. 19, 545-559 (2012)

24. Hinz, S., Jones, F.R., Schulte, K.: Micromechanical modelling of shear deformation of a $90^{\circ}$-ply in Glare at elevated temperatures. Comput. Mater. Sci. 39, 142-148 (2007)

25. Shi, Y., Swait, T., Soutis, C.: Modelling damage evolution in composite laminates subjected to low velocity impact. Compos. Struct. 94, 2902-2913 (2012)

26. ABAQUS: ABAQUS Version 6.10. Dessault Systemes, Providence (2010)

27. Shi, Y., Pinna, C., Soutis, C.: Modelling impact damage in composite laminates: a simulation of intra- and inter-laminar cracking. Compos. Struct. 114, 10-19 (2014)

28. Shi, Y., Pinna, C., Soutis, C.: Interface cohesive elements to model matrix crack evolution in composite laminates. Appl. Compos. Mater. 21, 57-70 (2014)

29. Shi, Y, Soutis, C. Modelling transverse matrix cracking and splitting of cross-pl composite laminates under four point bending. Theor. Appl. Fract. Mec. 2015

30. ASTM: D7136/D7136M-07. Standard Test Method for Measuring the Damage Resistance of a FibreReinforced Polymer Matrix Composite to a Drop-Weight Impact Event. American Society for Testing and Materials, Philadelphia (2007)

31. Léonard, F, Stein, J, Withers, PJ, Wilkinson, A. 3D Damage Characterisation in Composite Impacted Panels by LaboratoryX-ray Computed Tomography. 1st International Conference on Tomography of Materials and Structures, Ghent (Belgium), July 1-5, 2013

32. Léonard, F, Shi, Y, Soutis, C, Withers, PJ, Pinna, C. Impact damage characterisation of fibre metal laminates by X-ray computed tomography. Industrial Computed Tomography 2014 Conference, Wels (Austria), February, 2014

33. Hooputra, H., Gese, H., Dell, H., Werner, H.: A Comprehensive Failure Model for Crashworthiness Simulation of Aluminium Extrusions. Int J Crashworthiness. 9, 449-463 (2004)

34. ACG MTA ® 240 versatile cure film adhesive. Advanced composites group Ltd, Derbys, UK. https://www. acg.co.uk

35. Sung, N., Suh, N.: Effect of fiber orientation on friction and wear of fiber reinforced polymeric composites. Wear. 53, 129-141 (1979)

36. Schon, J.: Coefficient of friction of composite delamination surfaces. Wear. 237, 77-89 (2000)

37. Bing, Q, Sun, CT. Effect of transverse normal stress on mode II fracture toughness in fiber composites. In: 16th International conference on composite materials (ICCM16), Kyoto, Japan; 2007

Publisher's Note Springer Nature remains neutral with regard to jurisdictional claims in published maps and institutional affiliations. 